\title{
An experimental evaluation of the pharmacokinetics of fusidic acid in peritoneal dialysis
}

\author{
LOUISE ROWE, GLENNE FINDON and T. E. MILLER*
}

University of Auckland, Auckland, New Zealand

\begin{abstract}
Summary. Fusidic acid, an antimicrobial agent with activity against coagulase-positive and coagulase-negative staphylococci, has considerable potential for the management of staphylococcal peritonitis associated with continuous ambulatory peritoneal dialysis (CAPD). Whether fusidic acid reaches therapeutic levels in the dialysate once therapeutic serum levels have been achieved is not known. An animal model of CAPD that reproduced essential features of the clinical procedure was used to investigate this issue. Although oral administration was the preferred route, fusidic acid is not absorbed from the gastrointestinal tract of laboratory rats, and a subcutaneous injection of diethanolamine fusidate was used to achieve serum levels of the agent equivalent to those achieved clinically in man. In this model, fusidic acid concentrations up to 28 times the MIC for staphylococci were found in the dialysate when therapeutic levels of the agent were reached in the serum. The data provide support for continued experimental and clinical evaluation of the role of fusidic acid in CAPD-associated peritonitis.
\end{abstract}

\section{Introduction}

Staphylococcal peritonitis is a well recognised complication of continuous ambulatory peritoneal dialysis (CAPD). A frequency of 1.0-1.6 episodes of peritonitis/patient year has been reported from most large and multi-centre groups, although incidences outside the range often occur. ${ }^{1,2}$ Staphylococcal infection currently accounts for $65-75 \%$ of reported cases of peritonitis and of these, $30 \%$ are caused by the coagulase-negative staphylococcus, Staphylococcus epidermidis. Although several potentially effective antibiotics are available, few parenteral or orally administered antibiotics achieve therapeutic levels in the dialysate ${ }^{3-6}$ and antimicrobial therapy usually involves intraperitoneal instillation of the agents. Currently, vancomycin, together with an aminoglycoside or a broad-spectrum cephalosporin are commonly used. However, even with appropriate antimicrobial therapy, persistent peritonitis, defined as a lack of clinical improvement after 3-5 days of treatment, is observed in $5-15 \%$ of peritonitis episodes and accounts for $25-60 \%$ of the drop-outs from CAPD programmes. ${ }^{7}$ Of CAPD-related deaths, $\geqslant 15 \%$ have been attributed to this infection and experienced centres have reported the risk of dying from a peritonitis episodes to be $>2 \%{ }^{8}$

Received 30 Jan. 1991 ; accepted 24 April 1991.

* Correspondence should be sent to Dr T. E. Miller, Department of Medicine, Fourth Floor, Auckland Hospital, Park Road, Auckland, New Zealand.
Therefore, there is a need for continued assessment of new or existing agents that may offer specific advantages over current protocols. Fusidic acid is one such agent. It is highly active against coagulasepositive and coagulase-negative staphylococci. Resistance to it, which is chromosomal in nature, may develop but does not appear to be a problem in clinical practice. ${ }^{9,10}$ It is well absorbed after oral administration, leading to serum levels of $15-30 \mathrm{mg} / \mathrm{L}$, well in excess of the MIC for staphylococci of $0.03-0.25$ $\mathrm{mg} / \mathrm{L} .{ }^{11}$ Fusidic acid is also widely distributed in tissues giving high concentrations in such diverse sites as sputum, ${ }^{12}$ synovial tissue, ${ }^{13}$ mucus, ${ }^{14}$ bone ${ }^{15}$ and pus. ${ }^{16}$ Whether fusidic acid reaches therapeutic levels in the dialysate after oral administration is, however, unknown. In the present study, an animal model of CAPD was used to investigate this issue.

\section{Materials and methods}

\section{Animals}

Adult female Dark Agouti (DA) rats weighing 180 $250 \mathrm{~g}$ were obtained from an inbred colony.

\section{CAPD model}

Rats were anaesthetised and two vertical incisions were made, one $3.0 \mathrm{~cm}$ in length through the right abdominal wall and the second, subcutaneously $0.5 \mathrm{~cm}$ long between the ears. A stainless steel trochar was 
fed through the head incision, under the skin and pushed between the skin and muscle layer across the ribcage, before piercing the abdominal muscle and entering the peritoneal cavity. The end of a $15-\mathrm{cm}$ length of Silastic ${ }^{\circledR}$ medical-grade tubing (Dow Corning Corporation, Michigan, USA; catalogue no. 601-325) was placed over the end of the cannula and anchored with a suture (4-O TI.Cron, Davis \& Geck, Gosport, Hants) loosely wound around the cannula between the two collars and secured to the abdominal muscle. The abdominal incision was then closed. A 1-cm cube of foam with a central $5-\mathrm{mm}$ hole was pushed over the cannula at the head end and glued in place. This was then placed under the skin to secure the tube and the incision was closed before another Silastic collar was pushed over the external cannula. Finally, a cap $5 \mathrm{~mm}$ long was fitted into the cannula, sealing the opening. Animals were treated prophylactically with $5 \mathrm{mg}$ of ciprofloxacin (intravenous infusion; Bayer New Zealand Ltd, Auckland, New Zealand) via the catheter at the time the cannula was inserted and again over the next 2 days to eliminate post-operative infection. Dialysis was performed on lightly anaesthetised animals with warmed Dianeal PD-2 (Travenol Laboratories Inc., Deerfield, USA) which was introduced into the peritoneum through the permanent indwelling cannula.

\section{Fusidic acid administration}

Fusidic acid (Fucidin; Leo Pharmaceutical Products, Ballerup, Denmark) was given to rats by the oral, intramuscular (i.m.) or subcutaneous (s.c.) route, at doses of $20-200 \mathrm{mg} / \mathrm{kg}$. Oral administration was with either crushed tablets or the oral suspension. For i.m. and s.c. treatment, a solution of intravenous diethanolamine fusidate was used. The i.m. dose was given in the thigh muscle and the s.c. dose in the loose skin of the back of the neck.

\section{Experimental procedure}

Two groups of animals, one with a cannula in place and the other non-cannulated, were adapted to dialysis by the daily intraperitoneal (i.p.) administration of $20 \mathrm{ml}$ of warmed Dianeal $1.5 \%$ for 3 days before they were given fusidic acid. On the fourth day, fusidic acid was administered shortly before the i.p. administration of $20 \mathrm{ml}$ of warmed Dianeal $4.25 \%$. The latter concentration of Dianeal had been found to cause fluid retention in the peritoneal cavity as happens in clinical dialysis in man. Blood samples were collected $0 \cdot 5,1,2$ and $4 \mathrm{~h}$ later from the tail vein of lightly anaesthetised animals. The serum was separated and stored at $-70^{\circ} \mathrm{C}$ until analysed. In animals with a cannula in place, fluid for analysis was drained off under gravity 0,2 and $4 \mathrm{~h}$ after administration of the drug. In non-cannulated animals, samples of peritoneal fluid were withdrawn at the same time intervals with a perforated 18 -gauge needle and a $1-\mathrm{ml}$ syringe.
These samples were also stored at $-70^{\circ} \mathrm{C}$ until analysed. Gentle abdominal massage was done before sampling to mix peritoneal contents.

Effect of sterile inflammation. To determine the effect of the local inflammatory response on fusidic acid levels in the peritoneal cavity, a sterile reaction was induced with sodium caseinate before the administration of the antibiotic. Sixteen animals (non-cannulated) were divided into two groups. One group was given $20 \mathrm{ml}$ of Dianeal $1.5 \%$ daily for 3 days and on the fourth day, $20 \mathrm{ml}$ of Dianeal $4.25 \%$ was given at the same time as the fusidic acid was administered. The second group was also dialysed with $20 \mathrm{ml}$ of Dianeal $1.5 \%$ on day 1 , but on days 2 and $3,12 \mathrm{ml}$ of Dianeal $1.5 \%$ and $8 \mathrm{ml}$ of sodium caseinate $6 \%$ were introduced; on day 4, $20 \mathrm{ml}$ of Dianeal $4.25 \%$ was given simultaneously with fusidic acid. Blood and peritoneal dialysate samples were taken from individual animals 1 and $2 \mathrm{~h}$ after fusidic acid administration respectively.

\section{Biological assay for fusidic acid}

Fusidic acid was assayed by the agar-diffusion technique with a clinical isolate of $S$. aureus, sensitive to fusidic acid, as the test organism. The test strain was grown overnight in nutrient broth and $1 \mathrm{ml}$ of a 1 in 10 dilution of the culture in saline was added to $120 \mathrm{ml}$ of casamino acid-yeast extract agar at $47^{\circ} \mathrm{C}$. This was poured into a $23 \times 23-\mathrm{cm}$ assay plate and allowed to solidify. A cork borer was used to punch out 7-mm diameter wells in the agar. A standard solution of diethanolamine fusidate (DEF) containing $200 \mathrm{mg} / \mathrm{L}$ was serially diluted in serum citrate phosphate diluent or Dianeal to achieve concentrations of $0 \cdot 15-10 \mathrm{mg} / \mathrm{L}$. These standards, each assayed in triplicate, were used to construct the standard curve. A serum and Dianeal sample, each containing DEF $20 \mathrm{mg} / \mathrm{L}$, were assayed as additional controls with each experiment. Serum samples were diluted 1 in 4 and 1 in 8 with serum citrate phosphate buffer and the peritoneal fluid samples were assayed undiluted; $60 \mu \mathrm{l}$ of each dilution, the standards and controls were added to the appropriate wells. Plates were incubated on a flat surface overnight at $37^{\circ} \mathrm{C}$ and the zones around each well were measured with digimatic callipers (Mitutoyo Inc., Japan). The values of each sample were determined from the respective standard curve, adjusted for the dilution factor, and the level of diethanolamine fusidate obtained was converted to the equivalent concentration of fusidic acid.

\section{Cytology}

A total white cell count in acetic acid $2 \%$ was done in a Neubauer haemocytometer (American Optical Corp., NY, USA). Differential cell counts were made on a cytospin preparation (Shandon Southern, Runcorn, Cheshire) of a sample of dialysate, diluted in Hanks' Balanced Salts Solution to give approximately $2 \times 10^{5}$ cells $/ \mathrm{ml}$ and stained with Leishmans' stain. 


\section{Statistical analysis}

Results were evaluated by the non-parametric Wilcoxon sum of ranks test.

\section{Results}

\section{Fusidic acid administration}

Oral administration of the tablet formulation and oral suspension of fusidic acid to DA rats in doses up to $200 \mathrm{mg} / \mathrm{kg}$ failed repeatedly to achieve fusidic acid serum levels of therapeutic significance $(<0 \cdot 1 \mathrm{mg} / \mathrm{L})$. Intramuscular injections of diethanolamine fusidate $(100 \mathrm{mg} / \mathrm{kg})$ gave fusidic acid levels up to $20 \mathrm{mg} / \mathrm{L}$, but adverse effects, including hindlimb weakness and necrosis, precluded further use of the route. However, subcutaneous administration, achieved levels and a pharmacological profile similar to those found in clinical use. Mean fusidic acid concentrations of 14 and $15 \mathrm{mg} / \mathrm{L}$ were observed 30 and $60 \mathrm{~min}$ after a single dose of $200 \mathrm{mg} / \mathrm{kg}$ was administered s.c. Side effects were limited to lesions at the site of injection. Repeated administration of this dose by the s.c. route over a 4-day period, did not lead to increased serum levels of fusidic acid (fig. 1).

\section{Fusidic acid levels in the peritoneal cavity}

Non-cannulated animals. The relationship between serum fusidic acid levels and the concentration of the agent in the dialysate was first studied under experimental conditions uncomplicated by the presence of an indwelling cannula. Animals were conditioned to the protocol by daily instillation of $20 \mathrm{ml}$ of warmed $1.5 \%$ dialysis fluid into the peritoneal cavity for 3 days before the administration of the agent. On the fourth day, diethanolamine fusidate $200 \mathrm{mg} / \mathrm{kg}$ was injected s.c.; at the same time, $20 \mathrm{ml}$ of $4.25 \%$ dialysate was given. Mean peritoneal fluid levels of $1 \cdot 6$ SD $0.9,2 \cdot 6$ SD $1.2,4.3 \mathrm{SD} 1.6$ and 3.6 SD $2.3 \mathrm{mg} / \mathrm{L}$ were found $0 \cdot 5,1,2$ and $4 \mathrm{~h}$, respectively after administration. There was no evidence of an increase in the fusidic acid level in the dialysate when multiple doses $(200 \mathrm{mg} /$ $\mathrm{kg}$, three times daily for 2 days, followed by a single dose on the third day) were given. In the latter case, mean levels of 1.1 SD $0.67,2.4$ SD 1.2, 2.3 SD 1.4 and $1.1 \mathrm{SD} 0.77 \mathrm{mg} / \mathrm{L}$ were obtained after similar time intervals (fig. 2).

Dialysate: serum fusidic acid ratio. In the previous experiments (figs. 1 and 2), serum and dialysate samples were obtained from two different groups of animals to reduce the stress of repeated sampling. In this experiment, the ratio of fusidic acid levels in the serum and dialysate was determined in individual animals. A protocol was used whereby animals were bled $1 \mathrm{~h}$ after diethanolamine fusidate administration and were then killed after $2 \mathrm{~h}$ to obtain a sample of peritoneal fluid. After a single s.c. dose of diethanolamine fusidate $200 \mathrm{mg} / \mathrm{kg}$, serum levels varied between 3.89 and $31.0 \mathrm{mg} / \mathrm{L}$ (fig. 3a). The ratio of dialysate to serum fusidic acid concentrations were in the range $6.4-24.5 \%$, mean $15 \mathrm{SD} 7 \%$, in the 12 animals studied. After multiple doses $(200 \mathrm{mg} / \mathrm{kg}$ three times daily for 2 days, followed by a single dose on the third day), serum levels of fusidic acid were between 3.8 and $36.0 \mathrm{mg} / \mathrm{L}$ (fig. 3b). Ratios of $8.6-38.5 \%$, mean $21 \mathrm{SD}$ $9.6 \%$ were obtained.

Fusidic acid levels in cannulated animals. The pharmacokinetics of fusidic acid transfer across the peritoneal membrane was examined in cannulated rats. A conditioning period and experimental protocol similar to that used in the non-cannulated animals was followed; the indwelling cannula was used to deliver dialysate into and out of the peritoneal cavity. A single s.c. dose of $200 \mathrm{mg} / \mathrm{kg}$ resulted in mean fusidic acid

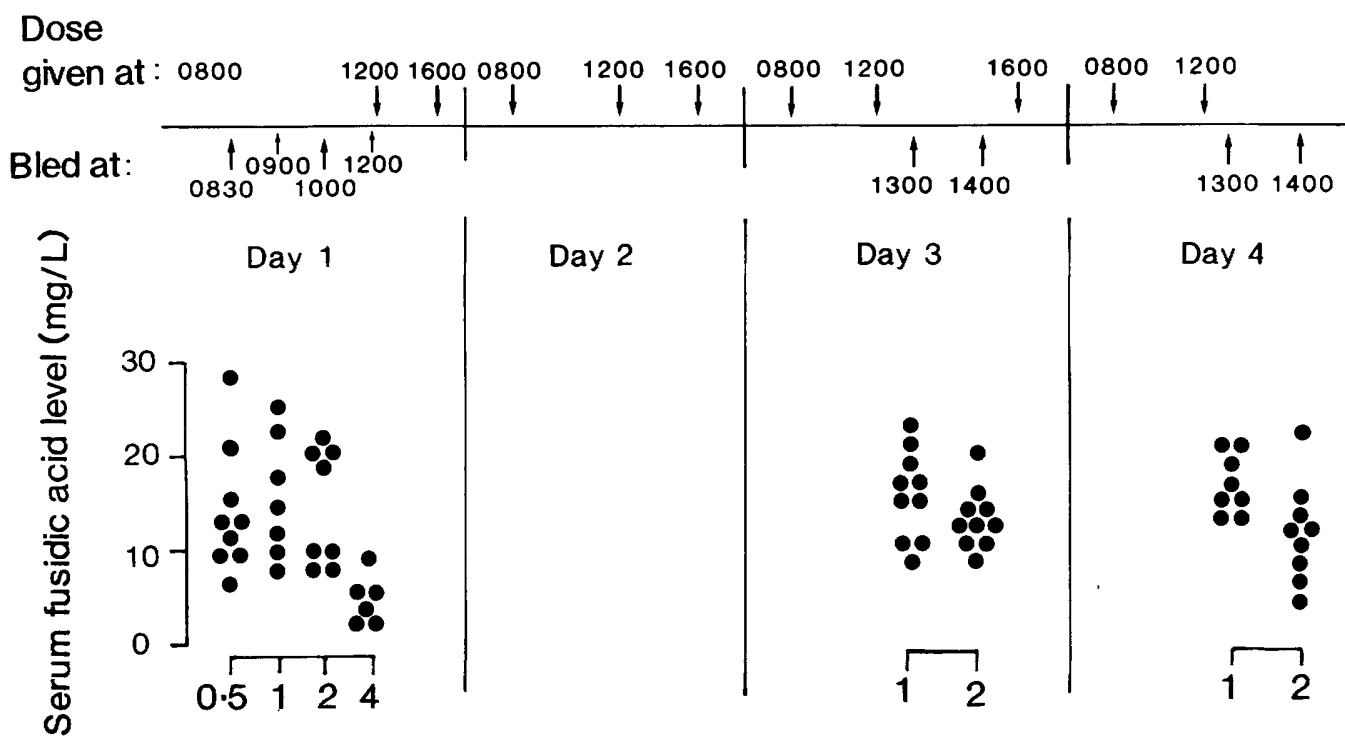

Hours after last dose

Fig. 1. Fusidic acid concentration in rat serum after single and multiple s.c. doses of diethanolamine fusidate $200 \mathrm{mg} / \mathrm{kg}$. 


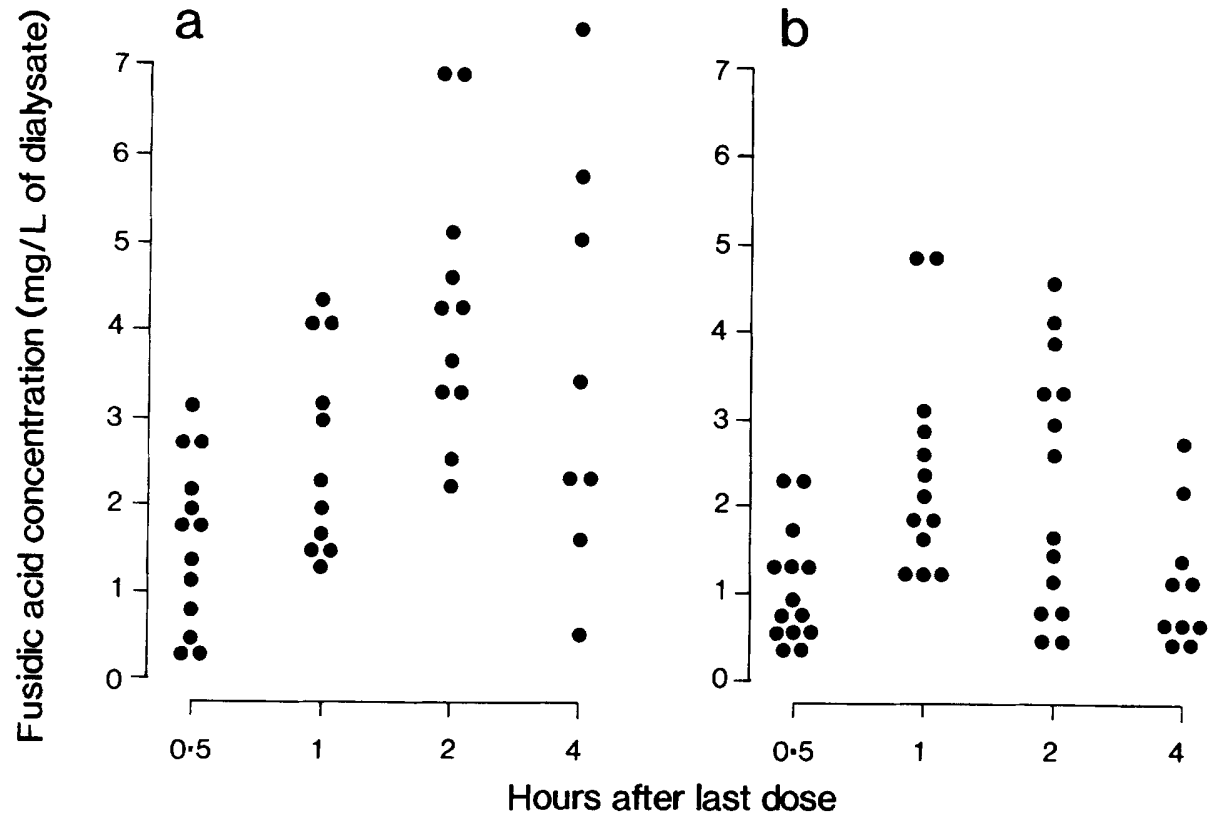

Fig. 2. Comparison of peritoneal fluid levels in non-cannulated animals after (a) single and (b) multiple s.c. doses of diethanolamine fusidate $200 \mathrm{mg} / \mathrm{kg}$.

concentrations in the peritoneal fluid of $0 \cdot 14 \mathrm{SD} 0 \cdot 16$, $0.43 \mathrm{SD} 0.30,0.89 \mathrm{SD} 0.88$ and $1.8 \mathrm{SD} 1.7 \mathrm{mg} / \mathrm{L}$ respectively, $0 \cdot 5,1,2$ and $4 \mathrm{~h}$ after administration. Multiple dosing gave average levels of $0.76 \mathrm{SD} 0.49$, $0.63 \mathrm{SD} 0.24,1.4 \mathrm{SD} 0.62$ and $1.1 \mathrm{SD} 0.37 \mathrm{mg} / \mathrm{L}$ at the equivalent sampling times (fig. 4).

\section{Inflammation and fusidic acid pharmacokinetics}

Effect of cannulation. Experiments were done to determine the effect that implanting a foreign body

a

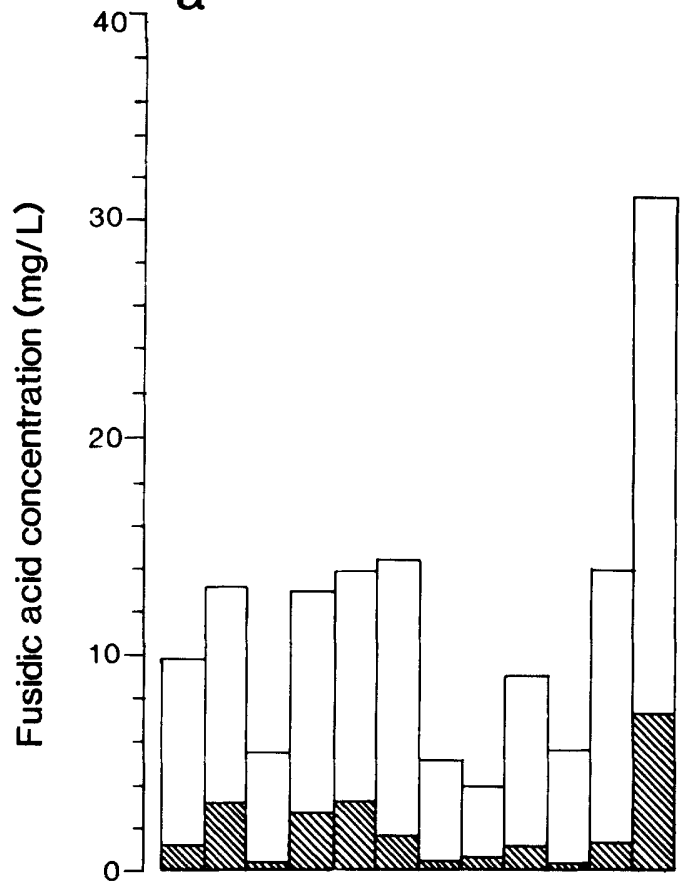

might have on inflammatory mechanisms in the peritoneal cavity. Saline, and Dianeal 1.5 and $4.25 \%$ were added to the peritoneal cavity of animals with and without indwelling cannulae and samples were taken immediately and 2 and $4 \mathrm{~h}$ later for leucocyte counts. Apart from a response to saline $4 \mathrm{~h}$ after instillation, non-cannulated animals showed little response to the two dialysis solutions. However, when saline was introduced into the peritoneal cavities of cannulated animals, a 17-fold increase in total leucocyte numbers occurred; similarly, there was a noticeable response to the two Dianeal solutions (table).

b

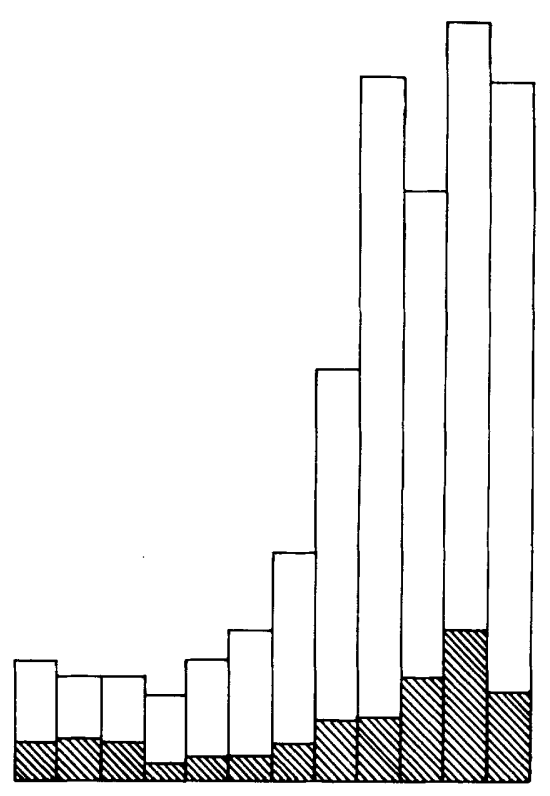

Individual animals

Fig. 3. The relationship between fusidic acid concentrations in serum $(\square)$ and peritoneal fluid (ש) after (a) single and (b) multiple s.c. doses of diethanolamine fusidate $200 \mathrm{mg} / \mathrm{kg}$. 


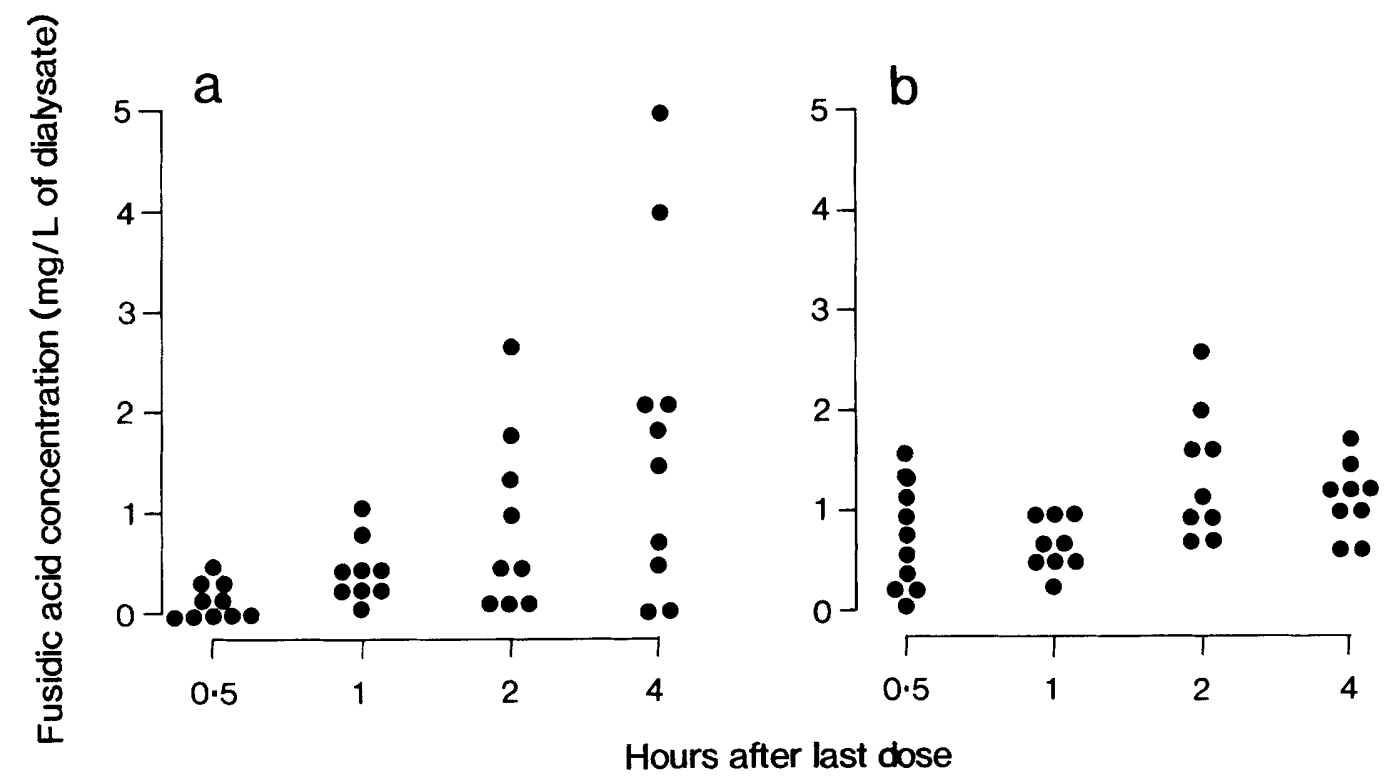

Fig. 4. Comparison of peritoneal fluid levels of fusidic acid in cannulated animals after (a) single and (b) multiple s.c. doses of diethanolamine fusidate $200 \mathrm{mg} / \mathrm{kg}$.

Serum levels of fusidic acid in the animals in which sterile inflammation was induced by administration of sodium caseinate were significantly lower than in their control group (2.9 SD 0.54 vs 3.8 SD $0.72 \mathrm{mg} / \mathrm{L}$, $\mathrm{p}=0.01$ ), and resulted in a substantial increase in the peritoneal fluid to serum ratio in these animals $(8 \% v s$ $28 \%$ ) (fig. 5).

\section{Discussion}

This study was done to determine whether serum levels of fusidic acid equivalent to clinically achieved levels in man would, in a rat model of CAPD, be associated with therapeutic levels of the agent in the dialysate. The stimulus for such an investigation arose from the continuing need to evaluate agents with therapeutic potential in the management of staphylococcal peritonitis associated with CAPD. Although studies of this nature are best done with clinical material, ethical constraints commonly demand that proposals for clinical investigations be supported by laboratory data from animal models.

The model of CAPD used in these experiments simulated the essential features of the procedure in man. Daily dialysis over a 21 -day period had no effect on biochemical or haematological parameters and animals maintained body weight and remained alert and active over this period (unpublished observations).

Initial attempts to use the oral route for the administration of fusidic acid were unsuccessful because the agent did not appear to be absorbed and could not be demonstrated in the serum. However, s.c. injection of diethanolamine fusidate resulted in levels of fusidic acid in the serum equal to those we had hoped to achieve by oral administration. When the procedure was used to obtain serum levels equivalent to those achieved clinically in man, the administration of a single dose of diethanolamine fusidate gave fusidic acid concentrations in the dialysate of $6-24 \%$ of the serum levels. This concentration was 4-28 times the MIC for staphylococci $(0.03-0.25 \mathrm{mg} / \mathrm{L}){ }^{11}$ Determination of dialysate to serum ratios in animals given multiple doses of fusidic acid gave similar results. One additional finding of interest was the increase in dialysate to serum ratio of fusidic acid in animals with an experimentally induced sterile peritonitis. Few studies have examined intraperitoneal antibiotic kinetics during peritonitis and most therapeutic protocols are based on drug kinetics across the normal

Table. Peritoneal fluid total leucocyte count

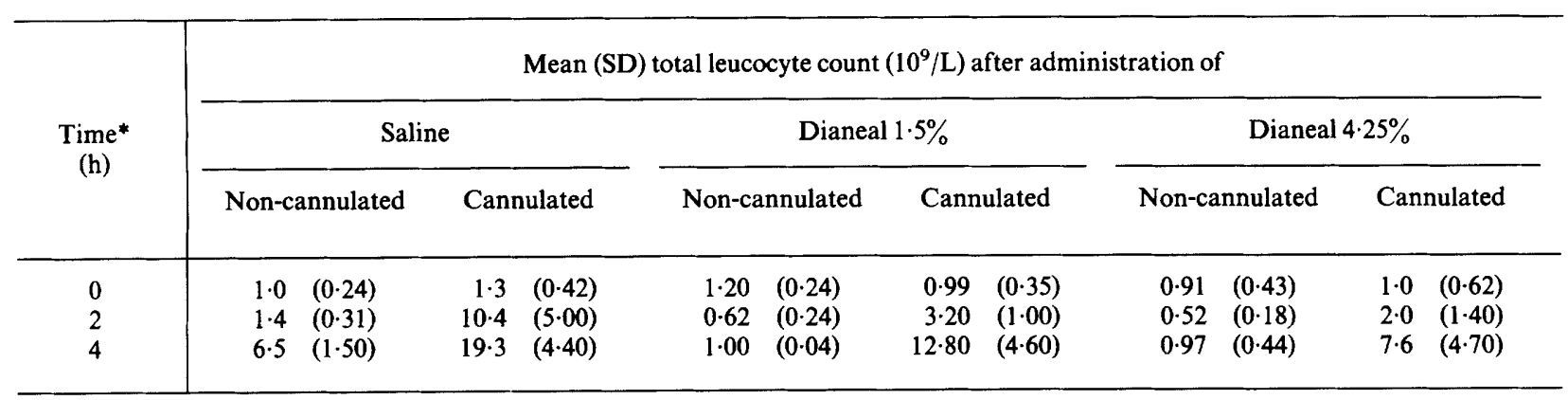

* After instillation of $20 \mathrm{ml}$ of saline, or Dianeal 1.5 or $4.25 \%$. 


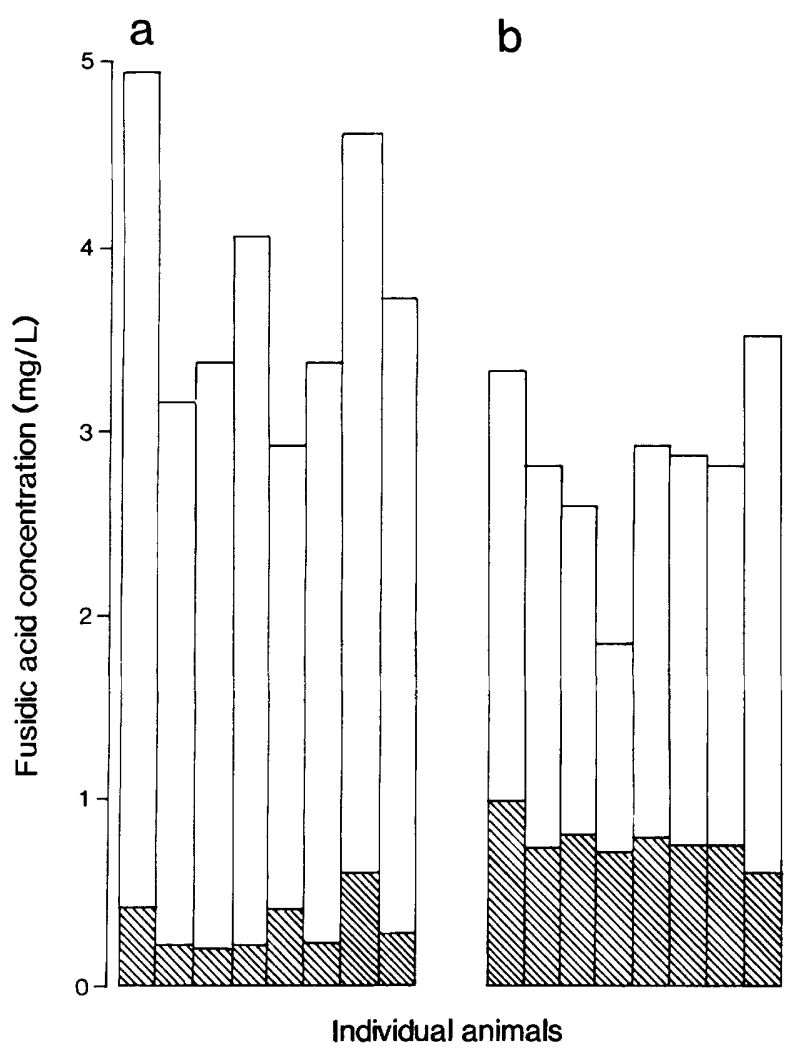

Fig. 5. Serum ( $\square$ ) and peritoneal fluid (ש) levels of fusidic acid in (a) control and (b) sodium caseinate-stimulated animals.

peritoneum, ${ }^{17}$ which may or may not reflect events complicated by infection and inflammation.

Current antimicrobial therapy for staphylococcal peritonitis usually involves the i.p. instillation of a cephalosporin, flucloxacillin or vancomycin, and, although most staphylococcal infections respond to these agents, therapeutic failures are not uncommon and complete eradication may require removal of the catheter. ${ }^{18}$ Even the quinolone group of antibiotics, which have theoretical advantages over existing agents, ${ }^{19}$ have not been universally effective in resolving this complication. ${ }^{20}$ Therefore, there is clearly a requirement for additional antibiotics for treating CAPD-associated staphylococcal peritonitis.

Fusidic acid in its oral and parenteral preparations offer several features that suggest a role for the agent in clinical practice. The pharmacokinetics of a new film-coated oral preparation of sodium fusidate are of particular interest-the agent is well absorbed and shows non-linear characteristics leading to greater than expected maximum serum concentrations. ${ }^{21}$ With MIC values of $0.03-0.25 \mathrm{mg} / \mathrm{L}$ for both $S$. aureus and $S$. epidermidis, including the $\beta$-lactamase producing strains, and serum concentrations reaching levels up to 100 times the latter figures, ${ }^{22}$ good responses have been obtained in several staphylococcal infections which, generally, have been difficult to treat. ${ }^{23-27}$ The agent appears to penetrate into relatively inaccessible sites ${ }^{15,28,29}$ and could be useful in eliminating $S$. epidermidis embedded in dense accumulations of extracellular slime on the peritoneal catheters. ${ }^{30}$ Other useful characteristics in patients with compromised renal failure include the findings that only a small amount of the antibiotic is excreted by the kidney in an active form and that there is no demonstrable crossresistance between fusidic acid and other antibiotics.

The ability of an antibiotic to penetrate into the extravascular tissues and body spaces is governed by several factors, including the concentration gradient from serum to tissue, binding to proteins in serum and tissue, molecular size, $\mathrm{pK}$ value and lipid solubility. Pharmacokinetic profiles based on the chemical characteristics of individual agents are not always accurately predictive, as, for example, the finding that protein-bound cephalosporins such as cephalothin and cefazolin achieve concentrations in the peritoneal cavity similar to those of the poorly bound aminoglycosides. Our current observation that clinically effective serum levels of fusidic acid are associated with therapeutically useful levels of the agent in the dialysate during CAPD in rats, suggests that, although highly protein bound, other compensating factors act to release a pool of antibiotic as the protein content of the milieu decreases.

The data obtained with the animal model of CAPD, demonstrating that therapeutic serum levels of fusidic acid were associated with potentially effective concentrations of the agent in the dialysate, have provided a firm basis for further laboratory, experimental and clinical studies. These will help to determine the role of fusidic acid in the management of staphylococcal peritonitis, commonly associated with this procedure. Further experiments are clearly warranted to assess the ability of the agent to contain experimentallyinduced staphylococcal peritonitis. Clinical studies will also be required to confirm the experimental data and evaluate the efficiency of the agent in man during therapeutic CAPD.

\section{References}

1. Heaton A, Rodger RSC, Sellars L et al. Continuous ambulatory peritoneal dialysis after the honeymoon: review of experience in Newcastle 1979-84. Br Med J 1986; 293: 938-941.

2. Nissenson AR, Gentile DE, Soderblom RE, Oliver DF, Brax $C$, the Medical Review Board, NCC \#4, Los Angeles, California. Morbidity and mortality of continuous ambulatory peritoneal dialysis: regional experience and longterm prospects. Am J Kidney Dis 1986; 7: 229-234.

3. Glew RH, Pavuk RA, Shuster A, Alfred HJ. Vancomycin

pharmacokinetics in patients undergoing chronic intermittent peritoneal dialysis. Int J Clin Pharmacol Ther Toxicol $1982 ; 20: 559-563$.

4. Somani P, Shapiro RS, Stockard H, Higgins JT. Unidirectional absorption of gentamicin from the peritoneum during continuous ambulatory peritoneal dialysis. Clin Pharm Ther $1982 ; 32: 113-121$.

5. Blevins RD, Halstenson CE, Salem NG, Matzke GR. Pharmacokinetics of vancomycin in patients undergoing continuous ambulatory peritoneal dialysis. Antimicrob Agents Chemother $1984 ; 25$ : 603-606.

6. Boeschoten EW, Rietra PJGM, Krediet RT, Visser MJ, Arisz L. 
CAPD peritonitis: a prospective randomized trial of oral versus intraperitoneal treatment with cephradine. J Antimicrob Chemother 1985; 16: 789-797.

7. Nolph, KD, Cutler, SJ, Steinberg SM, Novak JW. Continuous ambulatory peritoneal dialysis in the United States: a three-year study. Kidney Int 1985; 28: 198-205.

8. Fenton SSA, The University of Toronto Collaborative Dialysis Group. Peritonitis related deaths among CAPD patients. Peritoneal Dialysis Bulletin 1983; 3: Suppl: 9S-11S.

9. Taylor G, Bloor K. Antistaphylococcal activity of fucidin. Lancet $1962 ; 1$ : 935-937.

10. Crosbie RB. Treatment of staphylococcal infections with "fucidin". Br Med J 1963; 1: 788-794.

11. Reeves DS. Review-The pharmacokinetics of fusidic acid. $J$ Antimicrob Chemother 1987; 20: 467-476.

12. Saggers BA, Lawson D. In vivo penetration of antibiotics into sputum in cystic fibrosis. Arch Dis Child 1968; 43: 404409.

13. Sattar MA, Barrett SP, Cawley MID. Concentrations of some antibiotics in synovial fluid after oral administration, with special reference to antistaphylococcal activity. Ann Rheum Dis $1983 ; 42: 67-74$.

14. Saggers BA, Lawson D. Some observations on the penetration of antibiotics through mucus in vitro. $J$ Clin Pathol 1966; 19: 313-317.

15. Chater EH, Flynn J, Wilson AL. Fucidin levels in osteomyelitis. J Irish Med Assoc 1972; 65: 506-508.

16. Güttler $F$, Tybring L. Interaction of albumin and fusidic acid. Br J Pharmacol 1971; 43: 151-160.

17. McIntosh ME, Smith WGJ, Junor BJR, Forrest G, Brodie MJ. Increased peritoneal permeability in patients with peritonitis undergoing continuous ambulatory peritoneal dialysis. Eur J Clin Pharmacol 1985; 28: 187-191.

18. Walshe JJ, Morse GD. Infectious complications of peritoneal dialysis. In: Nissenson AR et al. (eds) Clinical dialysis, 2nd edn. Norwalk, CT, Appleton \& Lange. 1990: 301-318.
19. Rubinstein E, Adam D, Moellering R, Waldvogel F. International symposium on new quinolones. Rev Infect Dis 1988 10 Suppl 1: S1-S271.

20. Rose TF, Ellis-Pegler R, Collins J, Small M. Oral pefloxacin mesylate in the treatment of continuous ambulatory peritoneal dialysis associated peritonitis: an open noncomparative study. J Antimicrob Chemother $1990 ; 25$ : $853-$ 859.

21. MacGowan AP, Greig MA, Andrews JM, Reeves DS, Wise R. Pharmacokinetics and tolerance of a new film-coated tablet of sodium fusidate administered as a single oral dose to healthy volunteers. J Antimicrob Chemother $1989 ; 23,409$ 415.

22. Verbist L. The antimicrobial activity of fusidic acid. $J$ Antimicrob Chemother 1990; 25 Suppl: B1-5.

23. Jensen $\mathrm{K}$, Lassen HCA. Combined treatment with antibacterial chemotherapeutical agents in staphylococcal infections. $Q$ J Med 1969; 38: 91-106.

24. Rowling DE. Further experience in the management of chronic osteomyelitis. J Bone Joint Surg 1970; 52B : 302-307.

25. Cartwright RY, Hall GH. Management of shunt infection. $B r$ Med J 1972; 4 : 46.

26. Liddy $\mathrm{N}$. Intravenous fusidic acid in the newborn. Lancet 1973 ; 1: 621 .

27. Kanski, JJ. Treatment of late endophthalmitis associated with filtering blebs. Arch Ophthalmol 1974; 91: 339-343.

28. Deodhar SD, Russell F, Dick WC, Nuki G, Buchanan WW Penetration of sodium fusidate (fucidin) in the synovial cavity. Scand $J$ Rheumatol $1972 ; 1: 33-39$.

29. de Louvois J, Gortvai P, Hurley R. Antibiotic treatment of abscesses of the central nervous system. Br Med J 1977; 2: 985-987.

30. Evans RC, Holmes CJ. Effect of vancomycin hydrochloride on Staphylococcus epidermidis biofilm associated with silicone elastomer. Antimicrob Agents Chemother 1987; 31: 889894. 